\title{
Iliolumbar Artery
}

National Cancer Institute

\section{Source}

National Cancer Institute. Iliolumbar Artery. NCI Thesaurus. Code C52859.

A blood vessel arising from the internal iliac artery that supplies blood to the pelvic muscles and bones. 